\title{
Design and Research on Sheller for the Sunflower Seeds
}

\author{
Le Zong ${ }^{1, a}$, Kaibao Wang $^{* 1, b}$, Delei Zhou ${ }^{1, \mathrm{c}}$, Bo Zhu ${ }^{1}$, Cheng Yan ${ }^{1}$ \\ ${ }^{1}$ College of Mechanical Engineering, Beihua University, Jilin, Jilin, 132021, China \\ a149535819@qq.com, a'wangkaibao@126.com, ${ }^{\circ} 876214622 @ q q . c o m$
}

Keywords: Sunflower Seeds; Shelling Operation; Optimization Design Method; Extrusion Device; Virtual Prototype Technology

\begin{abstract}
The sunflower oil that has rich nutritional value is high-quality nutrition oil. The quality of oil products was impacted seriously by a lot of harmful substances that contained in sunflower seed shell. The characteristic of sunflower seeds are the kernel is smaller and the shell density is large. The shelling operation is quite difficult with the characteristic. The shelling devices for the sunflower seeds based on optimization design method and dynamics analysis is introduced in the paper. The shelling devices for the sunflower seeds can be used in the place of processing factory and individual workshop. The structure of shelling devices was designed with the 3d modeling software. In the research, the virtual prototype technology was used to simulate the kinematics and dynamics characteristics of the mechanical system. The feasibility of the design scheme of mechanical system was proved with the simulation analysis results. The equipment has advantages of the structure is compact, safe and reliable, easy to use. The research of the shelling devices for sunflower seeds can be regarded as the reference of the related research.
\end{abstract}

\section{Introduction}

The percentage of oil in the sunflower seeds is $28 \% \sim 50 \%$, and abundant nutrient substance like Linoleic acid and Vitamin A were included in the sunflower seeds oil. But the process of oil manufacture must being done after the shell being removed, since the quality of oil can be effected seriously by the hazardous material that included in the sunflower shell. The existing congeneric products both at home and abroad can be divided into five categories based on their working principle. They are Knife Plate mode, Scraper mode, Turbine mode, Centrifugal mode and Physical Strength mode, among which the Knife Plate mode is the most common one. By use the Knife Plate mode Sheller, productivity can be raised, but the degree of grinding and energy consumption can be too serious. In order to increase the productivity while at the same time reduce the degree of grinding, the Sunflower Seeds' Sheller was designed to meet the requirement of production.

\section{Overall design scheme of the shelling devices for the sunflower seeds}

The Sheller was made up of the Feedstock unit, the Reorder unit, the Twin-Roll unit, the Support-Separate unit, the Separate unit and the Circle unit.

In this device, the theory of becking was used to shucking the outer skin based on the Roller Gear mechanism. Initially, the space between two Roller Gear can be adjusted by govern the Adjusting Screw, and then Sunflower Seeds will be dumped into the Feedstock unit, in which the separation process will be completed according to the size of Sunflower Seeds. After the motor was started, the Sunflower Seeds will be sent to the decladding unit in the same direction under the control of toothed plate. While at the same time, the Double Gear Roller mechanism will reverse, and the Sunflower Seeds that fall into the gap between two Gear Roller will be supported by Support-Chip while at the same time the process of becking is in progress, after which the crushed Sunflower Seeds will be sent into the Separate unit, and that uncrushed will be sent back to the feedstock until they were crushed successfully. The overall design scheme is shown in Fig. 1.

*Kaibao Wang: Corresponding author; e-mail:wangkaibao@126.com; phone:18604497787 


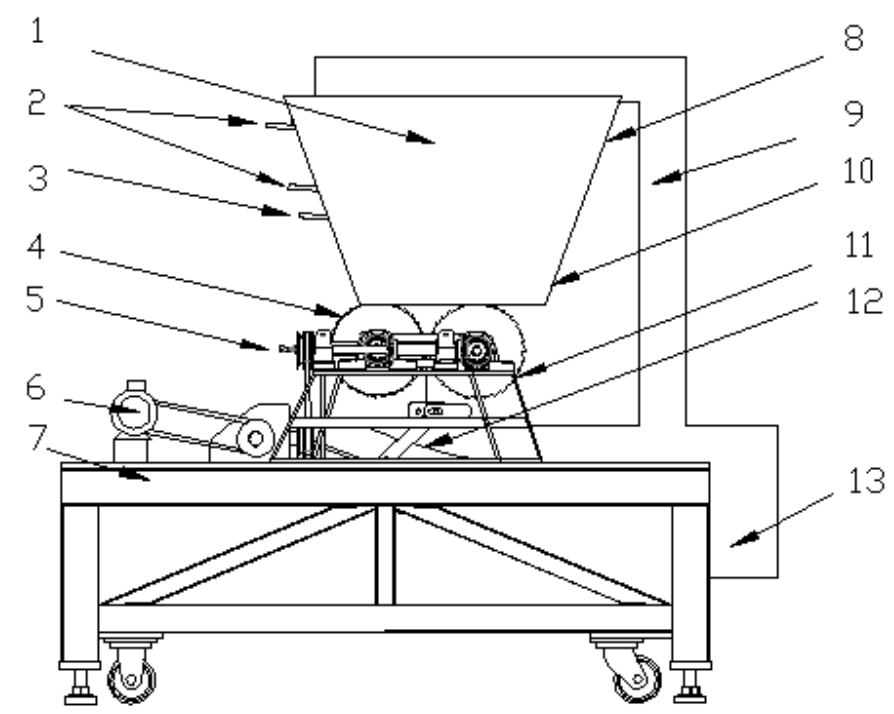

Fig. 1 Over Solution Design of the Sunflower Seeds' Sheller: 1、Charging Spout; 2、Vibratory Screen Piece; 3、Base Board; 4、Double Gear Roller Mechanism; 5、Adjusting Screw; 6、Electric Motor; 7、Body Frame; 8、Upper Screening Export; 9、Circle Device; 10、Lower Screening Export; 11、Support Frame; 12、13、Separate Apparatus

\section{Structure design of the shelling devices for the sunflower seeds}

Structure design of the feed stock device. The Feedstock device was made up of the Charging Spout, the Upper Screening Export, the Unpunched Plate, the Angular Surface and the Sequencing Roller. When it is working, the minor Sunflower seeds were separated by the Ostiole Screening Export, and then the bigger ones were separated by the Large Screening Export. In order to make sure the Sunflower Seeds lay flat on the Sequencing Baseboard when they were sent in to the Segregation Apparatus, the space between the Roller and the Baseboard should be larger than the side width and smaller than the side length. The structure of the feed stock device is shown in Fig. 2.

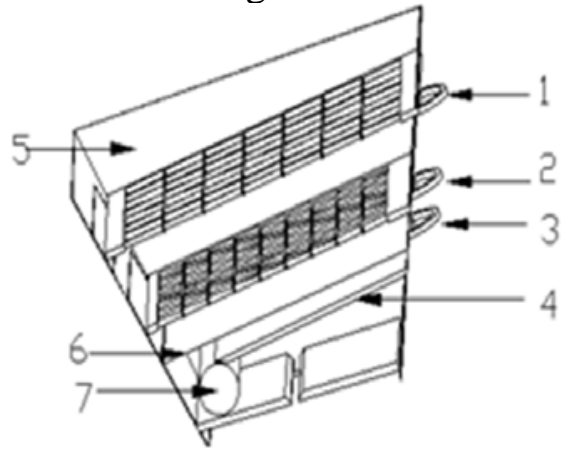

Fig. 2 Structure Design of the Feeder Unit

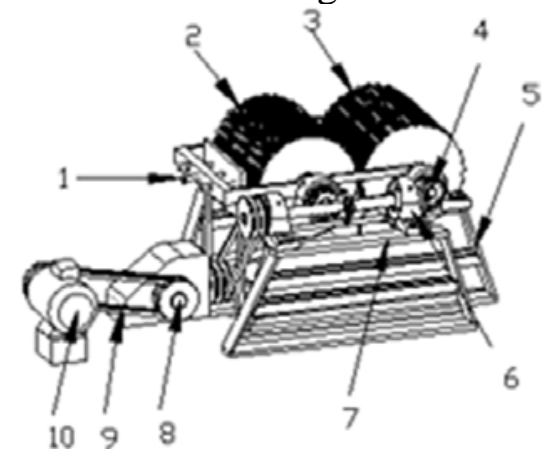

Fig. 3 Structure Design of Gear Roller

Structure design of the double gear roller mechanism. The Double Gear Roller Mechanism was made up of the Left Gear Roller, the Right Gear Roller, the Adjusting Screw Rod, the Supporting Base, the Sliding Groove, the Supporting Device and the Pulley. In the process of Decladding, the bottom surface was supported by the Supporting Device, the top surface of Sunflower Seeds were crushed by the Gear Roller. The structure of the double gear roller mechanism is shown in Fig. 3.

Structure Design of the Support-Separate device. The Support-Separate device was made up of the Pulley, the Connecting Link, the Slider, the Slider Groove and the Support-Separate Plate. The Slider and Bars will be driven by the Pulley, and the Support-Separate plate make an reciprocating motion along with the Slider in the Slider Groove. The function of the device is to make the Sunflower Seeds drop on the Separate Plate, while at the same time keeping those dropping into the Tooth Roller away from fall out through the space between the Gear Roller. The top surface of the 
Sunflower was crushed by the Rotating Gear Roller. Then the Sunflower Seeds and its hull will fall into the Segregation Apparatus. The structure of the support-separate device is shown in Fig. 4.

\section{Dynamics simulation analysis of the shelling devices for the sunflower seeds}

The constant speed of 600r/min was applied to the Gear Roller according to the facility request. The reverse torque of $435400 \mathrm{~N}$ mm was applied on the Gear Roller. The jump function of STEP (time,0,0d,0.2,1.38d) was applied between the Gear Rollers. The virtual prototype of the device is shown in Fig. 5.

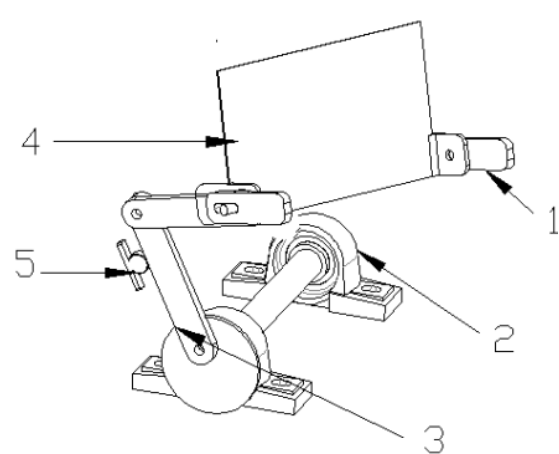

Fig. 4 Structure Design of the Support-Separate Mechanism Device

The simulation with an operate time of $6 \mathrm{~s}$ and a step size of 0.1 was implemented after the constrained condition were applied. According to the simulation result, a relatively small velocity change was caused by the reacting force of the Sunflower Seeds that crushed by the Gear Roller mechanism. And the excessive Gear Roller's acceleration driven by the electric motor. In the operation process, the Support-Separate Slider make an reciprocating motion. The velocity of Pulley is $1200 \mathrm{r} / \mathrm{min}$, the time was set as $0.05 \mathrm{~s}$, below is the result of simulation based on ADAMS/Postprocessor. The simulation results curve of the device is shown in Fig. 6 and Fig. 7.

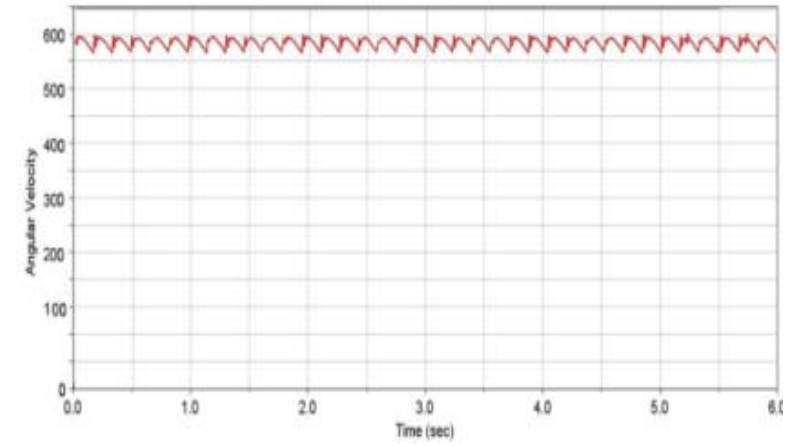

Fig. 6 Angular Velocity of Decladding Device

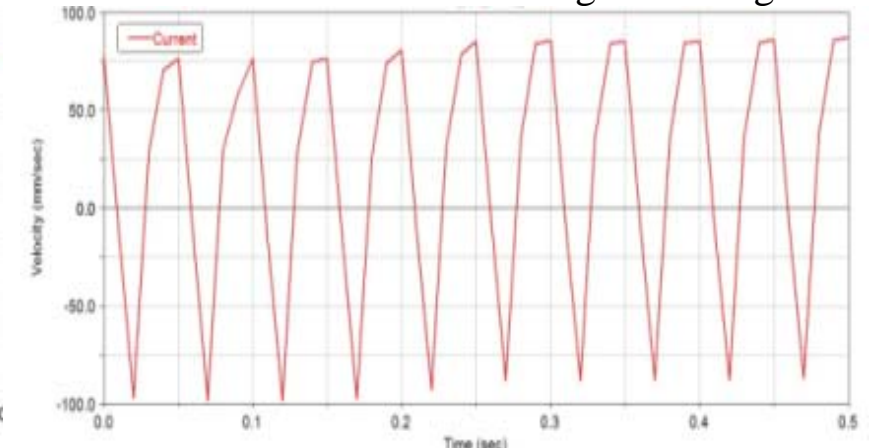

Fig. 7 Slider's Curve of Support-Separate Device According to the simulation result, the Decladding function can be fulfilled in the working condition. This proved that the device based on roller principle has high practical value.

\section{The finite element analysis on the stress of Sunflower seeds}

The average length of Sunflower Seeds is $20 \mathrm{~mm}$, its width and altitude is $6 \mathrm{~mm}$ and $4 \mathrm{~mm}$. The kernel of Sunflower Seeds is $20 \mathrm{~mm}$, its width and altitude is $4 \mathrm{~mm}$ and $2 \mathrm{~mm}$. The model of Sunflower Seeds was built according to the above statistical data. The modulus of elasticity was set as $3 \times$ $10^{9} \mathrm{~N} / \mathrm{m}^{2}$, the Poisson Ratio is $3 \times 10^{8} \mathrm{~N} / \mathrm{m}^{2}$, the Yield Strength is $2 \times 10^{7} \mathrm{~N} / \mathrm{m}^{2}$. The under surface was select as bearing surface, and an collision force more than $2 \mathrm{~N}$ has been applied on its two side faces. The force analysis model of the sunflower seed is shown in Fig. 8. The finite element analysis model of the sunflower seed is shown in Fig. 9. 


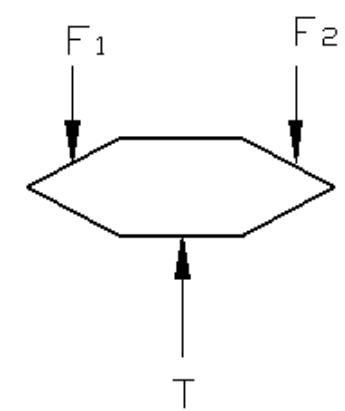

Fig. 8 The Force Diagram of Sunflower Seeds

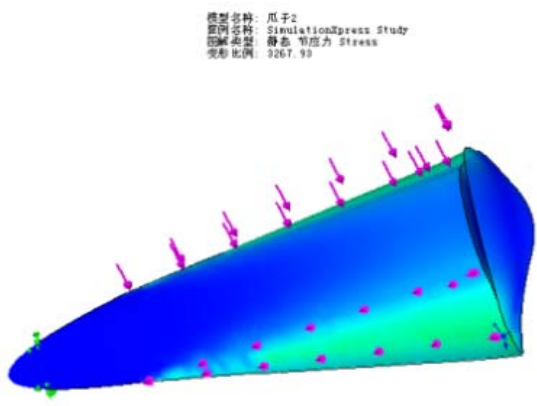

Fig. 10 The Shift Diagram

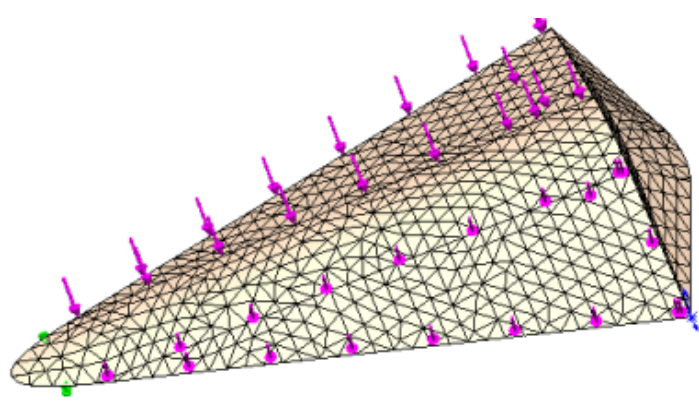

Fig. 9 The Arrow Diagram of Sunflower Seeds

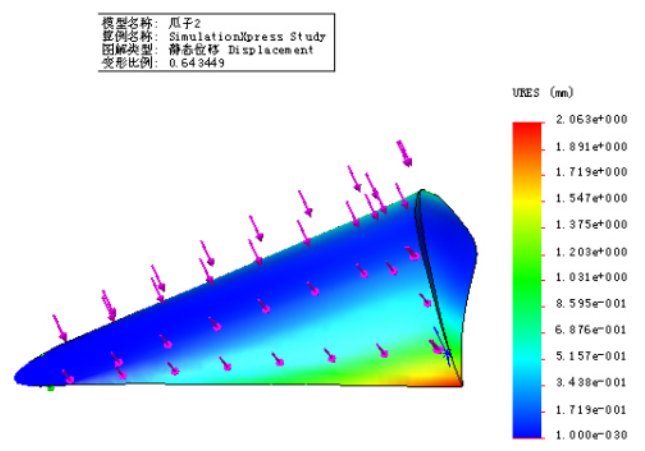

Fig. 11 The Deformation Stress Diagram

The finite element analysis results are shown in Fig. 10 and Fig. 11. Through the above analysis we can know that the actual application value of the Sunflower Seeds' Sheller has been authenticated. The efficiency of Decladding was improved while at the same time the probability of pulverize was cut down to a great degree.

\section{Conclusion}

This paper explains the application situation and development status of the shelling devices for the sunflower seeds based on optimization design method and dynamics analysis. The structure of the working units on the shelling devices was designed based on the existing mechanism. The commercial virtual prototype software ADAMS was used to simulate the rotation angular velocity. The stress of sunflower seed was analysed with the finite element analysis software. The research proved that the development of the shelling devices for the sunflower seeds is of great significance to the development and advancement of society in china.

\section{Reference}

[1] Seronei Chelulei Cheison, Zhang Wang, Shi-Ying Xu. Use of response surface methodology to optimize the hydrolysis of whey protein isolate in a tangential flow filter membrane reactor. Journal of Food Engineering . 2007.

[2] JANJAI S,MAHAYOTHEE B,LAMLERT Net al. Diffusivity shrink-age and simulated drying of litchi fruit(Litchi Chinensis Sonn.). Journal of Food Engineering . 2010.

[3] TREVOR O, LAKSHMI N,NEIL W, etal. Hot water treatments for the control of rots on harvested litchi(Litchi chinensis Sonn.)fruit. Postharvest Biology and Technology . 2004.

[4] Box G E P, Behnken D W. Some new three level designs for the study of quantitative variables. Technometrics . 1960.

[5] Sharma G P, Prasad S. Drying of garlic (Allium sativum) cloves by microwave-hot air combination. Journal of Food Engineering . 2001.

[6] Dunford NT, King JW. Phytosterol Enrichment of Rice Bran Oil by a Supercritical Carbon Dixide Fractionation Technique. Journal of Food Science . 2000. 